Western University

Scholarship@Western

Physical Therapy Publications

Physical Therapy School

$5-20-2019$

Ease of Caregiving for Children: Re-Validation of Psychometric Properties of the Measure for Children with Cerebral Palsy up to 11 Years of Age.

Mohammed S Alghamdi

Lisa A Chiarello

Lisa Avery

Robert J Palisano

Follow this and additional works at: https://ir.lib.uwo.ca/ptpub

Part of the Physical Therapy Commons

Citation of this paper:

Alghamdi, Mohammed S; Chiarello, Lisa A; Avery, Lisa; and Palisano, Robert J, "Ease of Caregiving for Children: Re-Validation of Psychometric Properties of the Measure for Children with Cerebral Palsy up to 11 Years of Age." (2019). Physical Therapy Publications. 56.

https://ir.lib.uwo.ca/ptpub/56 


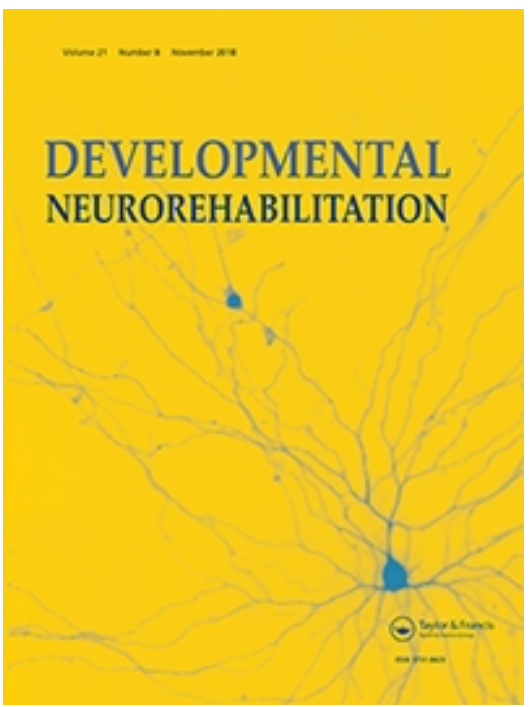

\section{Ease of Caregiving for Children: re-validation of psychometric properties of the measure for children with cerebral palsy up to 11 years of age}

\begin{tabular}{|r|l|}
\hline Journal: & Developmental Neurorehabilitation \\
\hline Manuscript ID & TPDR-2018-0078.R2 \\
\hline Manuscript Type: & Original Research \\
\hline Keywords: & $\begin{array}{l}\text { Physical caregiving, Family-centered Care, Cerebral Palsy, Ease of } \\
\text { Caregiving, Measurement }\end{array}$ \\
\hline \multicolumn{2}{|l}{} \\
\hline
\end{tabular}

\section{SCHOLARONE Manuscripts}




\begin{abstract}
Purpose: To re-validate stability and hierarchal ordering of items, test-retest reliability, and construct validity of the Ease of Caregiving for Children measure for parents of children with cerebral palsy (CP) up to 11 years of age.
\end{abstract}

Methods: Participants were 613 parents of children with CP between 1.5-11 years of age. Parents completed Ease of Caregiving for Children and both parents and therapists classified children's levels of gross motor, manual and communication functions.

Results: Rasch analysis indicated acceptable fit of items, stable item calibration, and logical ordering of items by difficulty. Test-retest reliability was good: ICC $=0.69$ (95\% CI $0.52-0.81)$. For construct validity, ease of caregiving was higher for parents of children with higher functioning compared to parents of children with lower functioning, $p<0.001$.

Conclusions: Ease of Caregiving for Children is a unidimensional, reliable and valid measure of physical caregiving for parents of children with CP 1.5-11 years. 
of the measure supported the undimensionality and hierarchical ordering of items by difficulty 14. The measure demonstrated high internal consistency (Cronbach's alpha =was 0.92) ${ }^{14}$ and acceptable test-retest reliability, $\operatorname{ICC}(2,1)=0.73,(95 \% \mathrm{CI}, 0.50$ to 0.86$){ }^{14}$. Construct validity of the measure was examined using the known-groups method in which the known groups were children's levels of gross motor function ${ }^{14}$, according to the Gross Motor Function Classification System ${ }^{20}$ (GMFCS). Parents of children without motor delay reported higher ease of caregiving scores compared with parents of children with CP. Among parents of children with CP, parents of children in level I reported the highest ease of caregiving scores followed by parents of children in levels II and II. Parents of children in levels IV and V reported the lowest ease of caregiving compared to parents of children in levels I-III. The ability to measure change over a one-year period was supported for children in levels I-III but not children in levels IV-V ${ }^{21}$. The effect size, however, was small (Cohen's $d=0.49$ for children in GMFCS level I and 0.35 for children in levels II-III) ${ }^{21}$.

Our research team recognized the need for re-validation of the psychometric properties of the Ease of Caregiving for Children measure for parents of children with CP across a broader age range that includes preschool and school aged children. Inconsistent evidence exists on the effects of children's age on parental caregiving ${ }^{16-18,22}$ and thus we were uncertain if the psychometric properties of the measure would change. In addition, available evidence suggests that limitations in motor and communication functions of children with CP are associated with challenges in parental caregiving $4,14,23,24$ and it is important to consider both children's age and functional abilities when evaluating the psychometric properties of the measure. The purposes of this study, therefore, were to: 1) determine the stability and hierarchal ordering of items and to create an interval-level scale; 2) examine test-retest reliability; and 3) examine the construct validity using know-groups method in which the known groups were children's levels of 
function in gross motor function, manual ability, and communication function and children's age.

\section{Methods}

\subsection{Design}

A cross sectional design was used. This study was part of two multi-site prospective studies, Move and PLAY and On Track. The Move and PLAY study was conducted to understand determinants of motor abilities, self-care, participation and playfulness of young children with cerebral palsy aged 1.5 to 5 years. The On Track study was conducted to create developmental trajectories and percentile curves for impairments in body structures/functions, associated health conditions, and participation of children with CP up to 12 years of age. Information on both studies can be found at the CanChild website (https://www.canchild.ca/en/research-in-practice/current-studies).

Prior to data collection, ethical approval of the study protocol was obtained from each university's Institutional Review Boards and, if required, from data recruitment/collection sites' ethics boards. Written informed consent was obtained from parents and assent was obtained from children when applicable.

\subsection{Participants}

The participants of this study were a convenience sample of 613 children with $\mathrm{CP}$ and their parents who were part of the Move and PLAY study $(\mathrm{n}=407)$ and the On Track study (n =206). Participants from Move and PLAY study were recruited from four regions in the United States (Greater Seattle, WA; Greater Philadelphia, PA; Greater Atlanta, GA, Greater Oklahoma City, OK) and six provinces in Canada (Newfoundland; Ontario; Manitoba; Saskatchewan; British Columbia; Nova Scotia). Participants from the On Track study were recruited only from three regions in the United States (Greater Seattle, WA; Greater Philadelphia, PA; Greater Atlanta, GA). 
Demographic information on the children and their parents from both studies is presented in Table 1. For the total sample, children were between 1.5 to 11 years of age with a mean age of $4.3(2.36)$ years, $56 \%$ were boys, and $66 \%$ were white. Parents of children were predominantly mothers $(90 \%)$ with a mean age of $36(8.17)$ years, and $76 \%$ were white. Fortytwo percent of parents were not employed at the time of the study and $72 \%$ had an educational level greater than high school.

For the reliability analysis of the measure, a sub-sample of 55 parents participated in the test-retest reliability of the Ease of Caregiving for Children Measure, 33 of which were from the Move and PLAY study. The reliability sub-sample consisted of 35 boys and 20 girls with mean age of $5.4(2.9)$ years, and across all GMFCS levels $(I=21 ; I I=7 ; \mathrm{III}=8 ; \mathrm{IV}=8 ; \mathrm{V}=$ 11). Parents had mean age of 35.8 (8.1) years and were predominantly mothers (80\%).

\subsection{Measures}

\subsubsection{Ease of Caregiving for Children Measure}

The Ease of Caregiving for Children ${ }^{14}$ is a reliable and valid parent-report measure of physical caregiving for parents of children with CP. Parents rate their level of difficulty when physically assisting their children in 12 activities including mobility, positioning, and self-care. Parents are instructed to rate the level of difficulty of caregiving tasks using a 5-point Likert Scale: 1 = "very difficult"; 2 = "somewhat difficult"; 3 = "little difficulty"; 4 = "no difficulty"; $5=$ "no help is needed". Parents are instructed to consider four factors when rating the level of difficulty: safety, physical demands, time, and confidence. The measure can be competed in a paper-and-pencil format within 5 to 10 minutes. The total summed score of the measure can be converted to an interval level score using the scoring system devised from the Rasch analysis. Higher scores indicate greater ease of caregiving for parents.

\subsubsection{Classification Systems}


Gross Motor Function Classification System (GMFCS) ${ }^{20}$, Manual Ability Classification System (MACS) ${ }^{25,26}$, and Communication Function Classification System (CFCS) ${ }^{27}$ are 5-level classification systems that are designed for children with CP (2 to 18 years) to classify their self-initiated movement, use of hands in daily life activities, and effectiveness sending and receiving information, respectively. For each classification system, children classified at level I have the highest functioning and children classified at level V have the lowest functioning. The psychometric properties of the three classification systems are summarized in Table 2. The classification systems can be retrieved from the following websites

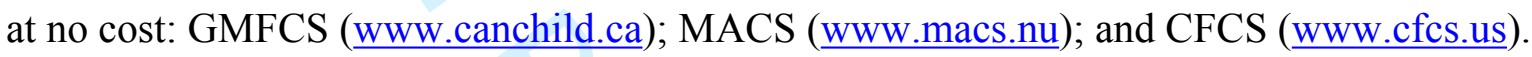

\subsection{Procedure}

Parents completed the Ease of Caregiving for Children measure during the first data collection point in the Move and PLAY and On Track studies. Parents and therapists classified children's GMFCS levels. Parents and therapists from the On Track study additionally classified children's levels of function using the MACS and CFCS. For the Move and PLAY study, therapists classified children's GMFCS level based on observation and discussion with parents on children's abilities. For the On Track study, parents and therapists independently classified children's levels of functions and their classifications were the same or consensus was reached following discussion $98 \%$ of the time for GMFCS, $97 \%$ for MACS and $94 \%$ for CFCS. If consensus was not reached, the research team decided to use parent's classification unless the therapist provided a rational justification ${ }^{28}$. For reliability testing of the Ease of Caregiving measure, a subgroup of parents completed the measure a second time with an interval of 5 to 44 days after the first visit.

\subsection{Data analysis}


Descriptive statistics were computed for all variables. All statistical analyses were conducted using SPSS software (SPSS Statistics for Windows, Version 23.0. Armonk, NY: IBM Corp.), unless stated otherwise.

\subsubsection{Rasch Analysis}

The Rasch model of item response analysis ${ }^{29}$ was used to determine the hierarchical ordering of items by difficulty and to create an interval level scoring system. Model fitting was conducted using the mixRasch package ${ }^{30}$ in R 3.2.4, using the Partial Credit Model (PCM) ${ }^{29}$.

The main assumption of the Rasch model is the unidimensionality of a measure; that all items evaluate a single latent trait. There is no single test to determine unidimensionality; instead this assumption was evaluated using five analyses: 1) the dominant factor method ${ }^{31}$; 2) scree plots; 3 ) the very simple structure criterion (VSS) ${ }^{32}$; 4) the comparative data (CD) method ${ }^{33}$; and 5) fit of items to the Rasch model. Rubio et al. ${ }^{31}$ suggested that a dominant factor is present if the ratio of the first factor's eigenvalue is 5 times the second factor's eigenvalue. The VSS method computes a VSS index, which varies from 0 to 1 for multiple solutions. The solution that maximizes the VSS index is regarded an optimal solution. The fit of items to the Rasch model was analyzed with two statistics, the unweighted average score residual, termed the outfit and the information-weighted residual, the infit. Linacre ${ }^{34}$ states the following for infit statistics values: $<0.5$ are overly predictable, $0.5-1.5$ productive for measurement, 1.5-2.0 unproductive, but not degrading and, $>2.0$ the noise dominates useful information.

The appropriateness of the rating scale used for the measure (5-point Likert Scale; $1=$ very difficulty to $5=$ no help is needed) was evaluated by examining the item characteristic curves. The characteristic curves provide visual representation of the performance of the 5point rating scale to evaluate: 1) the order of the rating options for each item (most to least 
difficult); 2) the use of each rating option (most selected option vs. least selected option); and 3) the position of rating options on the continuum of ease of caregiving.

The results of the Rasch analysis are item calibrations (which reveal the item hierarchy) and person measures. Item calibrations (measured in logits) range from negative to positive infinity and are constrained to have a mean of zero. Items with high positive calibration values are associated with more difficult caregiving tasks and items with large negative calibration values are associated with less difficult caregiving tasks. The person measures are based on the total sum score for all items and were re-scaled to lie on the interval of 0 to 100 . The table to transform raw scores to scaled scores is presented in the Appendix.

The stability of item calibrations was examined by randomly splitting the sample into two distinct sub-samples. Rasch analysis was performed for both sub-samples and Shrout and Fleiss' intraclass correlation $\mathrm{ICC}_{2}$ was used to compare the agreement in item calibrations between the two sub-samples ${ }^{35}$. A high correlation between the two sub-samples indicates stable item calibrations. Correlation between item estimates reported by Ward et al. ${ }^{14}$ and the revised item estimates from this study were examined.

\subsubsection{Reliability and Validity}

Data of 55 participants from the Move and Play and the On Track studies were analyzed to determine test-retest reliability of the measure. Intraclass correlation coefficient, $\operatorname{ICC}(2,1)$, was used to determine test retest reliability of Ease of Caregiving measure. The strength of ICC values were interpreted as follows: less than 0.4 as poor, 0.4 to 0.59 as fair, 0.6 to 0.74 as good, and 0.75 to 1.00 as excellent ${ }^{36}$. Because the time interval between test and retest varied between 5 to 44 days, we conducted a sensitivity analysis for participants $(n=39)$ who had an interval of 4 calendar weeks or less between test and retest visits. The sensitivity analysis was conducted with an assumption that Ease of Caregiving for Children scores would be more stable with shorter time intervals between test and retest. 
Data of the participants from the On Track study were analyzed to determine the construct validity of the measure. Data were missing for two participants and therefore data of 204 participants were used for the analyses. The construct validity was determined by knowngroups method using children's age and gross motor function, manual ability, and communication function levels as the known groups. Children were assigned to one of two groups based on their age: younger children (1.5 to 5.9 years) or older children (6 to 11 years). Children were also assigned to two groups based on their level of function in GMFCS, MACS, and CFCS: children with higher functioning (Levels I-II) or children with lower functioning (Levels III-V). Three separate two-way ANOVAs were used to examine the effect of children's age and level of function on ease of caregiving scores. The partial eta-squared was used to determine the magnitude of the effect of children's age and level of function on ease of caregiving ${ }^{37}$. Partial eta-squared was interpreted as follows: $=0.01$ indicates a small effect, $=0.06$ indicates a medium effect, and $=0.14$ indicates a large effect size ${ }^{37}$. An alpha level of $p<0.05$ was used for all analyses, unless stated otherwise.

The assumptions of the two-way ANOVAs were examined; outliers were assessed by visual inspection of boxplots, normality was assessed by Shapiro-Wilk's test for each cell, and the homogeneity of variance was assessed by Levene's test. The assumptions of normality and homogeneity of variance for the two-way ANOVAs were not satisfied. However, because of the large sample size $(n=204)$ and the ratio of the largest to smallest variance remaining less than $10: 1^{38}$, the analyses were deemed appropriate and robust to the violation of assumptions. Outliers were detected by visual inspection of the boxplots but we decided to retain them in the analyses because these were valid cases and only represented $0.04 \%$ of the sample size.

\section{Results}

\subsection{Rasch Analysis}


3.1.1. Unidimensionality: The dominant factor and scree plot methods indicated a single factor underlying the Ease of Caregiving for Children measure. For the dominant factor method, the ratio of the first eigenvalue (7.22) was 4.9 times the second eigenvalue (1.46). For the scree plot method, visual inspection of the plot indicated a single dominant factor. The comparative data (CD) method indicated that a four-factor structure minimized the root mean square residual eigenvalue $(\mathrm{RMSE}=0.06)$ compared to a single factor solution $($ RMSE $=0.17)$. For the VSS method, when items were allowed to load only on a single factor, the VSS index for the single factor solution was 0.94 and the VSS indices for the 2, 3 and 4-factor solutions varied from $0.57-0.37$. The fit of items to the Rasch model also supported the unidimensionality of the measure; results are presented in the following sections.

3.1.2. Item characteristic curves: Visual inspection of the item characteristic curves indicated that the 5 -point rating scale $(1=$ very difficult to $5=$ no help is needed $)$ is properly ordered. The 'Somewhat Difficult' rating option was the most under-used option; however, it was a rating option for several of the items. Therefore, this rating option was deemed appropriate and the 5-point rating scale was retained. Figure 1 shows the item characteristic curves for item 10 "to eat".

3.1.3. Item fit and item hierarchy: Item calibrations (logits) and Infit and Outfit values are presented in Table 5. The item calibrations (average item logits) varied from -0.88 to 0.78 and reflect the average item difficulty. Overall, the item infit statistics are all within an acceptable range. Item 7, put on/take off orthosis, displayed the highest infit value (1.85). The item-response map for the Ease of Caregiving for Children is presented in Figure 2. Items are ordered along the $\mathrm{Y}$-axis according to the difficulty of the caregiving tasks, based on parent response at the highest rating (no help needed), with item "to bathe" being ranked as most difficult task and item "position for sleeping" being ranked as least 
difficult task. The numbers plotted across the map correspond to the actual rating options of the measure. The placement of the numbers on the $\mathrm{X}$-axis corresponds to the Ease of Caregiving scaled score at which the probability of achieving at least that score or higher is $50 \%$, i.e. Thurstone thresholds ${ }^{29}$. The item endorsement map indicates a spread of calibrations owing to multiple rating options within each item.

3.1.4. Stability of item calibration: Using the Partial credit model, the correlation of the item estimates generated from two independent sub-samples $(n=306,307)$ was $\operatorname{ICC}(2,1)=$ 0.98, (95\% CI, 0.94 to 0.99$)$.

3.1.5. Correlation between original and revised item estimates: Correlation between original item estimates ${ }^{14}$ using the Rating Scale Model and the revised item estimates using Partial Credit Model was $r=0.94$, (95\% CI, 0.80 to 0.98$)$.

\subsection{Reliability of the Ease of Caregiving for Children Measure}

For the subgroup of parents who completed the measure twice, the $\operatorname{ICC}(2,1)$ was 0.69 , (95\% CI, 0.52 to 0.81 ) indicating good reliability. For the sensitivity analysis of test-retest reliability with a time interval of 4 calendar weeks or less, the $\operatorname{ICC}(2,1)$ was $0.75,(95 \% \mathrm{CI}$, 0.57 to 0.86$)$, indicating excellent reliability.

\subsection{Construct validity of the Ease of Caregiving for Children Measure}

Descriptive statistics for parental ease of caregiving by children's age and level of function for each of the three classification systems are presented in Table 3. For the influence of children's age and level of function on parental ease of caregiving, there was only one significant interaction: children's age and gross motor function level, $\mathrm{F}(1,200)=5.57, P=$ 0.019 , partial $=0.027$. No significant interaction was found between children's age and manual ability level $(\mathrm{F}(1,200)=0.65, P=0.42$, partial $=0.003)$ or between children's age and communication function level $(\mathrm{F}(1,200)=3.76, P=0.54$, partial $=0.018)$. Given that the interaction effect is significant for children's age and gross motor function level, an analysis 
of simple main effects for gross motor function level was conducted with Bonferrnoi adjustment and alpha level $P<0.025$. There was a significant difference in mean ease of caregiving scores between parents of younger children with higher functioning $(\mathrm{M}=57.6, \mathrm{SD}$ $=14.77)$ and parents of older children with higher functioning $(\mathrm{M}=64.3, \mathrm{SD}=17.11), \mathrm{F}(1,200)$ $=6.71, P=0.01$, partial $\quad=0.032$. However, no difference in mean ease of caregiving between parents of younger children with lower functioning $(\mathrm{M}=44.7, \mathrm{SD}=8.92)$ and parents of older children with lower functioning $(\mathrm{M}=42.9, \mathrm{SD}=8.21), \mathrm{F}(1,200)=0.53, P=0.47$, partial $=$ 0.003 .

Across all analyses, there were no significant main effects for children's age on parental ease of caregiving, $P>0.05$. There were significant main effects for children's level of function on parental ease of caregiving for gross motor function, $\mathrm{F}(1,200)=91.24, P<0.001$, partial $=0.31$; manual ability, $\mathrm{F}(1,200)=81.32, P<0.001$, partial $=0.29$; and communication function, $\mathrm{F}(1,200)=66.7, P<0.001$, partial $=0.25$. For all three classification systems, parents of children with higher functioning had a higher mean ease of caregiving compared to parents of children with lower functioning, $P<0.001$. Table 4 provides differences in parental ease of caregiving scores based on children's levels of function.

\section{Discussion}

The findings indicate that the Ease of Caregiving for Children is a unidimensional, reliable, and valid measure of physical caregiving of parents of children with CP 1.5 to 11 years. Across the five methods that were used to assess the unidimensionality, the findings indicate that the Ease of Caregiving for Children is measuring a single latent trait, physical caregiving. The Rasch analysis indicated that items (caregiving tasks) fit the Rasch model and have a stable and logical hierarchy. Although the fit of items to the Rasch model was acceptable, we reflected on the relatively higher infit value of item 7, put on / take off an orthosis, and decided to retain the item because the infit value was still below the Linacre's threshold of noise item that 
dominates useful information. We also believe that this item is of importance especially to parents of children who wear orthotics. The hierarchy for caregiving tasks (items) in the current study remained relatively stable compared to the original Rasch analysis reported in Ward et al.'s study ${ }^{14}$. The stability of item hierarchy is statistically supported by the observed high correlation between original and revised item estimates and visually evident in the item response map. This finding suggests that the perceived level of difficulty of caregiving tasks reported by parents is not dependent on children's age. For example, putting on/taking off clothes was a harder caregiving task and positioning a child for sleep was an easier caregiving task across both studies.

The partial credit model enabled us to generate an item response map (Figure 2) that provides useful information regarding the probability of achieving each caregiving task. Overall, parents with higher scaled scores completed more caregiving tasks with less difficulty and, therefore, have greater overall ease of caregiving. A scaled score of 20 indicates that there is a 50\% likelihood that all 12 tasks are "somewhat to very difficult". A scaled score of 40 indicates that there is a $50 \%$ likelihood that easier tasks (e.g. positioning for sleeping) are performed with "no difficulty" and harder tasks (e.g. bathing) with "a little difficulty". A scaled score of 60 indicates that there is a 50\% likelihood that children require "no help" for easier tasks and assistance is provided by parents with "no difficulty" for harder tasks.

The intervals on the item response map between scores corresponding to the ratings "somewhat difficult", "a little difficult", "no difficulty", and "no help needed" represent the average increase in score needed to move from one level of difficulty to the next. The large intervals between scaled scores corresponding to the ratings "no difficulty" and "no help needed" for most items suggest that providing no help, particularly for harder tasks, may not be easily attainable for children with $\mathrm{CP}$ due to their functional limitations. In contrast, the intervals between scaled scores that correspond to the ratings "somewhat difficult", "a little 
difficult", and "no difficulty" are smaller and similar across tasks reflecting that provision of physical assistance would be expected from parents of children with $\mathrm{CP}$ and the progression from one level of difficulty to the next is more readily attainable.

Differences in parental ease of caregiving based on children's levels of gross motor function, manual ability, and communication functions illustrate the measure's ability to discriminate between known groups, thus supporting the construct validity. As expected, parents of children with higher functioning (gross motor, manual, and communication functions) reported greater ease of caregiving compared to parents of children with lower functioning. Our findings for the influence of children's gross motor and manual functions on parental ease of caregiving are consistent with earlier research 14,16,24. Communication and speech impairments in children with CP have been linked to low parent-child interaction ${ }^{39}$. Our study adds that children's communication function does influence parent's ability to physically assist their children in daily life activities. The findings suggest that children's level of mobility, use of hands to manipulate objects, and ability to communicate with parents can determine the need and extent of parental physical assistance. These findings have implications for service providers to provide anticipatory supports and services (e.g. parent education, training, and use of assistive technology) that optimize parents' caregiving experience.

Our finding on the interaction between age and gross motor function suggests that children's age alone should not be considered a determinant of parental ease of caregiving for children with $\mathrm{CP}$ between 1.5 to 11 years of age. Differences in ease of caregiving based on children's age were evident only for parents of children with higher functioning (GMFCS levels I-II) with parents of older children (6-11 years of age) reporting greater ease of caregiving than parents of younger children (1.5-5 years of age). It can be expected that older children with higher gross motor function may have achieved independence in fulfilling many daily life activities and thus parents can anticipate greater ease in caregiving. In contrast, no 
differences in ease of caregiving based on children's age were found for parents of children with lower functioning (GMFCS levels III-V). We believe that the lack of difference in ease of caregiving based on children's age for children with significant mobility limitations may be attributable to the complex interaction of parent, child, and environmental factors such as parent's capacity for helping their children, children's physical size and level of independence in daily life activities, and availability of formal or informal support.

Our finding of lack of differences in ease of caregiving based on children's age extends the findings of Ward et al. ${ }^{14}$ that ease of caregiving did not differ by children's age for parents of children with CP between 1.5 to 5 years of age. In contrast, two previous studies reported a positive association between children's age and caregiver's perceived difficulty of caregiving for parents of children with CP aged 2 to 22 years ${ }^{16,17}$. Given that we only studied ease of caregiving for parents of children up to 11 years of age, we believe that differences in ease of caregiving based on children's age might be notable when children reach adolescence and their physical growth becomes more prominent.

\section{Implications for practice}

Service providers are encouraged to use Ease of Caregiving for Children as part of their assessment of children with CP during the initial and follow-up examinations. Ease of Caregiving for Children is a short measure that can be competed in 5 to 10 minutes and can help service providers to objectively document and guide interventions for ease of caregiving of parents of children with CP. Regardless of the practice setting, Ease of Caregiving for Children can be used to gain information about parents' perception of ease of caregiving. It also can be used to guide discussions with parents to identify their individual strengths, needs and concerns related to caregiving for their children, assist with anticipation of progression in parent's ease of caregiving for harder tasks, and to establish parent goals and focus of intervention. The updated version of the measure now includes spaces for parents to share their 
experiences related to each item and for service providers to documents their notes. The updated version can be found at the On Track study webpage: https://www.canchild.ca/en/research-in-practice/current-studies.

\section{Limitations and recommendations for research}

A limitation of this study is that we only re-validated selective psychometric properties of the measure (test-rest reliability, construct validity, and stability and hierarchal ordering of items). We also did not examine parent (e.g. self-efficacy) or environmental factors (e.g. availability of assistive technology), which would have added meaningful context to the findings. The sensitivity and responsiveness of the measure need to be established for parents of children and youth with CP before it can be used to measure change over time. Research on the Ease of Caregiving for Children is also needed to determine validity of the measure for parents of children and youth with other disabilities and health conditions. Conclusion

Our findings indicate that the Ease of Caregiving for Children is a reliable and valid measure that can be used to assess physical caregiving for parents of children with $\mathrm{CP}$ between 1.5 to 11 years of age. This study used a rigorous measurement approach to determine logical ordering of items, to re-validate the interval-level scoring system, and to support the construct validity of the measure. The Rasch analysis, using the Partial Credit Model, indicated that the items (caregiving tasks) are logically ordered and vary in difficulty. Across the three function classification systems (GMFCS, MACS, CFCS), parents of children with higher functioning reported greater ease of caregiving compared to parents of children with lower functioning. Differences in ease of caregiving based on children's age were evident only for parents of children with higher functioning (GMFCS levels I-II) with parents of older children reported greater ease of caregiving than parents of younger children. We encourage service providers to use the Ease of Caregiving for Children in conjunction with conversation to identify caregiving tasks that are of concern and to partner with families to develop individualized plans of care. 


\section{Acknowledgments}

This research was supported by Canadian Institutes of Health Research (MOP-81107 \&

MOP-119276), U.S. Department of Education, National Institute of Disability and

Rehabilitation Research, (H133G060254) and Patient-Centered Outcomes Research Institute

(5321). We acknowledge the Move and PLAY and On Track study teams, participating sites, children and their families. 


\section{References:}

1. Murphy NA, Christian B, Caplin DA, Young PC. The health of caregivers for children with disabilities: caregiver perspectives. Child Care Health Dev. 2007;33(2):180-187.

2. Brehaut JC, Garner RE, Miller AR, Lach LM, Klassen AF, Rosenbaum PL, Kohen DE. Changes over time in the health of caregivers of children with health problems: growthcurve findings from a 10-year Canadian population-based study. Am J Public Health. 2011;101(12):2308-2316.

3. Carona C, Silva N, Crespo C, Canavarro MC. Caregiving burden and parent-child quality of life outcomes in neurodevelopmental conditions: the mediating role of behavioral disengagement. J Clin Psychol Med Settings. 2014;21(4):320-328.

4. Wijesinghe CJ, Cunningham N, Fonseka P, Hewage CG, Østbye T. Factors associated with caregiver burden among caregivers of children with cerebral palsy in Sri Lanka. Asia Pac J Public Health. 2015;27(1):85-95.

5. Raina P, O'Donnell M, Rosenbaum P, Brehaut J, Walter SD, Russell D, Swinton M, Zhu B, Wood E. The health and well-being of caregivers of children with cerebral palsy. Pediatrics. 2005;115(6):e626-e636.

6. Marrón EM, Redolar-Ripol D, Boixadós M, Nieto R, Guillamón N, Hernández E, Gómez B. Burden on caregivers of children with cerebral palsy: predictors and related factors. Universitas Psychologica 2013;12(3):767-777.

7. Brehaut JC, Kohen DE, Raina P, Walter SD, Russell DJ, Swinton M, O'Donnell M, Rosenbaum P. The health of primary caregivers of children with cerebral palsy: how does it compare with that of other Canadian caregivers? Pediatrics. 2004;114(2):e182e191. 
8. Carona C, Crespo C, Canavarro M. Similarities amid the difference: Caregiving burden and adaptation outcomes in dyads of parents and their children with and without cerebral palsy. Res Dev Disabil. 2013;34(3):882-893.

9. Byrne M, Hurley D, Daly L, Cunningham C. Health status of caregivers of children with cerebral palsy. Child Care Health Dev. 2010;36(5):696-702.

10. Carona C, Pereira M, Moreira H, Silva N, Canavarro MC. The disability paradox revisited: Quality of life and family caregiving in pediatric cerebral palsy. J. Child Fam. Stud. 2013;22(7):971-986.

11. Guillamón N, Nieto R, Pousada M, Redolar D, Muñoz E, Hernández E, Boixadós M, Gómez-Zúñiga B. Quality of life and mental health among parents of children with cerebral palsy: the influence of self-efficacy and coping strategies. J Clin Nurs. 2013;22(11-12):1579-1590.

12. Ketelaar M, Volman M, Gorter J, Vermeer A. Stress in parents of children with cerebral palsy: what sources of stress are we talking about? Child Care Health Dev. $2008 ; 34(6): 825-829$.

13. Haley SM. Pediatric Evaluation of Disability Inventory (PEDI): Development, standardization and administration manual. PEDI Resarch Group; 1992.

14. Ward KD, Chiarello LA, Bartlett DJ, Palisano RJ, McCoy SW, Avery L. Ease of Caregiving for Children: a measure of parent perceptions of the physical demands of caregiving for young children with cerebral palsy. Res Dev Disabil. 2014;35(12):34033415.

15. Narayanan UG, Fehlings D, Weir S, Knights S, Kiran S, Campbell K. Initial development and validation of the Caregiver Priorities and Child Health Index of Life with Disabilities (CPCHILD). Dev Med Child Neurol. 2006;48(10):804-812. 
16. Hwang M, Kuroda MM, Tann B, Gaebler-Spira DJ. Measuring care and comfort in children with cerebral palsy: the care and comfort caregiver questionnaire. PM\&R 2011;3(10):912-919.

17. Andrews M, Bolt DM, Braun M, Benedict RE. Measuring exertion during caregiving of children and young adults with cerebral palsy who require assistance for mobility and self-care. Phys Occup Ther Pediatr. 2013;33(3):300-312.

18. Tadema AC, Vlaskamp C. The time and effort in taking care for children with profound intellectual and multiple disabilities: A study on care load and support. Br J Learn Disabil. 2010;38(1):41-48.

19. Geere J, Gona J, Omondi F, Kifalu M, Newton C, Hartley S. Caring for children with physical disability in Kenya: potential links between caregiving and carers' physical health. Child Care Health Dev. 2013;39(3):381-392.

20. Palisano RJ, Rosenbaum P, Bartlett D, Livingston MH. Content validity of the expanded and revised Gross Motor Function Classification System. Dev Med Child Neurol. 2008;50(10):744-50.

21. Palisano RJ, Chiarello LA, McCoy SW, Bartlett D, An M. Use of the Child Engagement in Daily Life and Ease of Caregiving for Children to Evaluate Change in Young Children with Cerebral Palsy. Phys Occup Ther Pediatr. 2015; 35(3):280-95.

22. Crowe TK, Florez SI. Time use of mothers with school-age children: A continuing impact of a child's disability. Am J Occup Ther. 2006;60(2):194-203.

23. McCann D, Bull R, Winzenberg T. The daily patterns of time use for parents of children with complex needs: A systematic review. J Child Health Care. 2012;16(1):26-52.

24. Prakash V, Patel AM, Hariohm K, Palisano RJ. Higher levels of caregiver strain perceived by Indian mothers of children and young adults with cerebral palsy who have limited self-mobility. Phys Occup Ther Pediatr. 2017;37(1):64-73. 
25. Eliasson A-C, Krumlinde-Sundholm L, Rösblad B, Beckung E, Arner M, Öhrvall AM, Rosenbaum P. The Manual Ability Classification System (MACS) for children with cerebral palsy: scale development and evidence of validity and reliability. Dev Med Child Neurol. 2006;48(07):549-554.

26. Plasschaert VF, Ketelaar M, Nijnuis M, Enkelaar L, Gorter JW. Classification of manual abilities in children with cerebral palsy under 5 years of age: how reliable is the Manual Ability Classification System? Clin Rehabil. 2009;23(2):164-170.

27. Hidecker MJC, Paneth N, Rosenbaum PL, Kent RD, Lillie J, Eulenberg JB, CHESTER J, Johnson B, Michalsen L, Evatt M. Developing and validating the Communication Function Classification System for individuals with cerebral palsy. Dev Med Child Neurol. 2011;53(8):704-710.

28. Bartlett DJ, Galuppi B, Palisano RJ, McCoy SW. Consensus classifications of gross motor, manual ability, and communication function classification systems between therapists and parents of children with cerebral palsy. Dev Med Child Neurol. 2016;58(1):98-99.

29. Masters GN, Wright BD. Rating Scale Analysis. Rasch Measurement. ERIC; 1982.

30. Willse JT. Mixture Rasch Models with JMLE. 2015. Retrieved from https://cran.rproject.org/web/packages/mixRasch/mixRasch.pdf

31. Rubio VJ, Aguado D, Hontangas PM, Hernández JM. Psychometric properties of an emotional adjustment measure: An application of the graded response model. Eur $\mathrm{J}$ Psychol Assess. 2007;23(1):39-46.

32. Revelle W, Rocklin T. Very simple structure: An alternative procedure for estimating the optimal number of interpretable factors. Multivariate Behav Res. 1979;14(4):403414. 
33. Ruscio J, Roche B. Determining the number of factors to retain in an exploratory factor analysis using comparison data of known factorial structure. Psychol Assess. $2012 ; 24(2): 282$.

34. Linacre JM. WINSTEPS Rasch measurement computer program. Chicago: WINSTEPS. com 2006.

35. Shrout PE, Fleiss JL. Intraclass correlations: uses in assessing rater reliability. Psychol Bull. 1979;86(2):420.

36. Cicchetti DV. Guidelines, criteria, and rules of thumb for evaluating normed and standardized assessment instruments in psychology. Psychol Assess. 1994;6(4):284.

37. Lakens D. Calculating and Reporting Effect Sizes to Facilitate Cumulative Science: A Practical Primer for t-tests and ANOVAs. Front Psychol. 2013; 26(4):863.

38. Tabachnick B, Fidell L. Using Multivariate Statistics Pearson New International Edition; 2014.

39. Pennington L, McConachie H. Predicting patterns of interaction between children with cerebral palsy and their mothers. Dev Med Child Neurol. 2001;43(2):83-90. 
Table 1. Demographic information for participants from Move and PLAY and On Track studies

\begin{tabular}{|c|c|c|c|}
\hline \multirow[t]{2}{*}{ Variable } & \multirow[t]{2}{*}{ Description } & \multicolumn{2}{|c|}{ Study } \\
\hline & & $\begin{array}{l}\text { Move and PLAY } \\
(n=407)\end{array}$ & $\begin{array}{l}\text { On Track } \\
(n=206)\end{array}$ \\
\hline Child age (Years) & Mean (SD) & $3.43(1.6)$ & $5.96(2.7)$ \\
\hline Child Sex & $\begin{array}{l}\text { Boys } \\
\text { Girls }\end{array}$ & $\begin{array}{l}228(56 \%) \\
179(44 \%) \\
\end{array}$ & $\begin{array}{l}117(56.8 \%) \\
89(43.2 \%) \\
\end{array}$ \\
\hline Child Race & $\begin{array}{l}\text { African American } \\
\text { Asian/ Pacific Islander } \\
\text { Hispanic/Latino } \\
\text { Native American } \\
\text { White } \\
\text { Other }\end{array}$ & $\begin{array}{l}31(7.6 \%) \\
17(4.2 \%) \\
18(4.4 \%) \\
11(2.7 \%) \\
284(69.8 \%) \\
46(11.3 \%) \\
\end{array}$ & $\begin{array}{l}32(15.9 \%) \\
9(4.5 \%) \\
16(7.8 \%) \\
\overline{123}(59.7 \%) \\
21(10.2 \%)\end{array}$ \\
\hline Child GMFCS & $\begin{array}{l}\text { Level I } \\
\text { Level II } \\
\text { Level III } \\
\text { Level IV } \\
\text { Level V } \\
\end{array}$ & $\begin{array}{l}146(35.9 \%) \\
47(11.5 \%) \\
51(12.5 \%) \\
73(17.9 \%) \\
90(22.1 \%) \\
\end{array}$ & $\begin{array}{l}52(25.2 \%) \\
46(22.3 \%) \\
25(12.1 \%) \\
40(19.4 \%) \\
43(20.9 \%) \\
\end{array}$ \\
\hline Child MACS & $\begin{array}{l}\text { Level I } \\
\text { Level II } \\
\text { Level III } \\
\text { Level IV } \\
\text { Level V } \\
\end{array}$ & 一 & $\begin{array}{l}29(14.1 \%) \\
76(36.9 \%) \\
36(17.5 \%) \\
41(19.9 \%) \\
24(11.7 \%) \\
\end{array}$ \\
\hline Child CFCS & $\begin{array}{l}\text { Level I } \\
\text { Level II } \\
\text { Level III } \\
\text { Level IV } \\
\text { Level V } \\
\end{array}$ & - & $\begin{array}{l}58(28.2 \%) \\
35(17 \%) \\
42(20.4 \%) \\
39(18.9 \%) \\
32(15.5 \%) \\
\end{array}$ \\
\hline Parent age (Years) & Mean (SD) & $34.6(8.1)$ & $39.1(7.5)$ \\
\hline Parent Race & $\begin{array}{l}\text { African American } \\
\text { Asian/ Pacific Islander } \\
\text { Hispanic/Latino } \\
\text { Native American } \\
\text { White } \\
\text { Other }\end{array}$ & $\begin{array}{l}34(8.4 \%) \\
19(4.7 \%) \\
23(5.7 \%) \\
9(2.2 \%) \\
319(78.4 \%) \\
3(0.7 \%) \\
\end{array}$ & $\begin{array}{l}32(15.9 \%) \\
8(4.0 \%) \\
11(5.5 \%) \\
\overline{146}(72.6 \%) \\
4(2.0 \%) \\
\end{array}$ \\
\hline $\begin{array}{l}\text { Parent relationship to } \\
\text { child }\end{array}$ & $\begin{array}{l}\text { Mother } \\
\text { Father } \\
\text { Others }\end{array}$ & $\begin{array}{l}371(91.1 \%) \\
21(5.1 \%) \\
15(3.6 \%) \\
\end{array}$ & $\begin{array}{l}182(88.4 \%) \\
16(7.8 \%) \\
6(2.9) \\
\end{array}$ \\
\hline $\begin{array}{l}\text { Total household } \\
\text { income }\end{array}$ & $\begin{array}{l}\text { Less than } 30,000 \\
30,000 \text { to } 44,999 \\
45,000 \text { to } 59,999 \\
60,000 \text { to } 74,999 \\
75,000 \text { or more } \\
\text { Prefer not to } \\
\text { answer/missing }\end{array}$ & $\begin{array}{l}86(21.1 \%) \\
51(12.5 \%) \\
55(13.5 \%) \\
46(11.3 \%) \\
155(38.1 \%) \\
14(3.4 \%)\end{array}$ & $\begin{array}{l}23(16 \%) \\
14(6.8 \%) \\
13(6.3 \%) \\
18(8.7 \%) \\
96(46.6 \%) \\
32(15.6)\end{array}$ \\
\hline Parent education & $\begin{array}{l}\text { High school or less } \\
\text { Community college } \\
\text { diploma; technical degree } \\
\text { University/graduate degree }\end{array}$ & $\begin{array}{l}131(32.1 \%) \\
110(27 \%) \\
166(40.7 \%) \\
\end{array}$ & $\begin{array}{l}36(17.5 \%) \\
48(23.3) \\
119(57.8 \%) \\
\end{array}$ \\
\hline
\end{tabular}


Table 2. Psychometric properties of the classification systems

\begin{tabular}{|c|c|c|c|}
\hline Psychometrics & GMFCS $^{\text {a }}$ & MACS $^{\text {b }}$ & CFCS $^{c}$ \\
\hline Reliability & $\begin{array}{l}\text { Reliability has been } \\
\text { investigated for } \\
\text { children with CP 2- } 18 \\
\text { years of age }{ }^{20} \text {. } \\
\text { - Moderate inter-rater } \\
\text { reliability ( } \kappa= \\
0.55 \text { ) for children } \\
\text { younger than } 2 \\
\text { years of age. } \\
\text { Substantial inter- } \\
\text { rater reliability ( } \kappa= \\
0.75 \text { ) for children } \\
\text { older than } 2 \text { years } \\
\text { of age. }\end{array}$ & $\begin{array}{l}\text { Reliability has been } \\
\text { investigated for } \\
\text { children with CP 2- } 18 \\
\text { years of age }{ }^{25,26} \text {. } \\
\text { - } \quad \text { Moderate inter- } \\
\text { observer reliability } \\
\text { ( } \kappa=0.55 \text { ) for } \\
\text { children under } 2 \\
\text { years of age; and } \\
\text { good inter-observer } \\
\text { reliability ( } \kappa= \\
0.67 \text { ) for children } \\
2-5 \text { years of age }{ }^{26} \text {. } \\
\text { High inter-rater } \\
\text { reliability (ICC }= \\
0.97 \text { ) for children } \\
4-18 \text { years of age } \\
26 \text {. }\end{array}$ & $\begin{array}{l}\text { Reliability has been } \\
\text { investigated for } \\
\text { children with CP 2- } 18 \\
\text { years of age }{ }^{27} \text {. } \\
\text { - Good inter-rater } \\
\text { reliability between } \\
\text { professionals ( } \kappa= \\
0.66) \text {. } \\
\text { Moderate inter- } \\
\text { rater reliability } \\
\text { between parents } \\
\text { and professionals is } \\
\text { moderate ( } \kappa= \\
0.49) \text {. } \\
\text { Very good test- } \\
\text { retest reliability ( } \kappa \\
=0.82) \text {. }\end{array}$ \\
\hline Validity & $\begin{array}{l}\text { Content and construct } \\
\text { validity have been } \\
\text { supported for children } \\
\text { with CP 2- } 18 \text { years of } \\
\text { age }{ }^{20} \text {. }\end{array}$ & $\begin{array}{l}\text { Content and construct } \\
\text { validity has been } \\
\text { supported for children } \\
\text { 4- } 18 \text { years of age }{ }^{25} \text {. }\end{array}$ & $\begin{array}{l}\text { Content and construct } \\
\text { validity has been } \\
\text { supported for children } \\
4-18 \text { years of age }{ }^{27} \text {. }\end{array}$ \\
\hline $\begin{array}{ll}\text { a. } & \text { Gross M } \\
\text { b. } & \text { Manual } \\
\text { c. } & \text { Commur } \\
\end{array}$ & $\begin{array}{l}\text { Function Classification Sy } \\
\text { ty Classification System } \\
\text { on Function Classification }\end{array}$ & & \\
\hline
\end{tabular}




\begin{tabular}{|l|c|c|c|c|c|c|}
\hline Table 3. Ease of Caregiving scores (mean and standard deviation) across function and age groups \\
\hline Age groups & \multicolumn{2}{|c|}{ GMFCS } & \multicolumn{3}{c|}{ MACS } & \multicolumn{3}{c|}{ CFCS } \\
\hline Younger Children & Levels I-II & Levels III-V & Levels I-II & Levels III-V & Levels I-II & Levels III-V \\
$(1.5$ to 5.9 years) & $(\mathrm{n}=47)$ & $(\mathrm{n}=40)$ & $(\mathrm{n}=52)$ & $(\mathrm{n}=35)$ & $(\mathrm{n}=44)$ & $(\mathrm{n}=43)$ \\
\hline Older Children & $64.3(17.11)$ & $42.9(8.21)$ & $62.0(16.74)$ & $43.7(10.91)$ & $63.1(16.77)$ & $44.0(10.90)$ \\
$(6$ to 11 years) & $(\mathrm{n}=49)$ & $(\mathrm{n}=68)$ & $(\mathrm{n}=52)$ & $(\mathrm{n}=65)$ & $(\mathrm{n}=48)$ & $(\mathrm{n}=69)$ \\
\hline Total & $61.0(16.27)$ & $43.5(8.49)$ & $59.9(15.39)$ & $43.3(9.96)$ & $60.4(15.96)$ & $44.7(10.67)$ \\
& $(\mathrm{n}=96)$ & $(\mathrm{n}=108)$ & $(\mathrm{n}=104)$ & $(\mathrm{n}=100)$ & $(\mathrm{n}=92)$ & $(\mathrm{n}=112)$ \\
\hline
\end{tabular}

\begin{tabular}{|l|l|l|l|l|}
\hline \multicolumn{2}{|l|}{$\begin{array}{l}\text { Table 4. Differences in Ease of Caregiving scores (estimated marginal mean and confidence interval) based on } \\
\text { children's levels of function }\end{array}$} & Estimated Marginal Mean & 95\% Confidence Interval & P value \\
\hline \multicolumn{2}{|c|}{ Function Levels } & & {$[58.40-63.46]$} & $P<0.001$ \\
\hline \multirow{2}{*}{ GMFCS } & Levels I-II & 61.93 & {$[41.30-46.25]$} & \\
\cline { 2 - 5 } & Levels III-V & 43.78 & {$[57.40-62.42]$} & $P<0.001$ \\
\hline \multirow{2}{*}{ MACS } & Levels I-II & 59.91 & {$[40.41-45.78]$} & \\
\cline { 2 - 4 } & Levels III-V & 43.10 & {$[57.54-62.99]$} & \\
\hline CFCS & Levels I-II & 60.27 & {$[42.32-47.39]$} & \\
\cline { 2 - 4 } & Levels III-V & 44.86 & & \\
\hline
\end{tabular}




\begin{tabular}{lrrrr}
\hline \multicolumn{5}{l}{ Table 5. Item measures (logits) and item fit for Ease of Caregiving for Children measure } \\
\hline Item & Logits & S.E. & Infit & Outfit \\
\hline moving at home/community & 0.34 & 0.05 & 0.90 & 0.90 \\
position for sleeping & -0.88 & 0.06 & 1.01 & 0.83 \\
position for feeding & -0.53 & 0.06 & 0.80 & 0.75 \\
position for bathing & 0.19 & 0.05 & 0.78 & 0.73 \\
position for playing & -0.57 & 0.05 & 0.79 & 0.68 \\
put on/take off clothes & 0.68 & 0.06 & 0.93 & 0.99 \\
put on/take off orthosis & 0.07 & 0.05 & 1.85 & 2.26 \\
to bathe & 0.78 & 0.06 & 0.80 & 0.82 \\
to use the toilet & 0.27 & 0.06 & 1.03 & 1.03 \\
to eat & -0.44 & 0.06 & 1.02 & 1.00 \\
to drink & -0.67 & 0.06 & 1.04 & 0.89 \\
in and out of car & 0.76 & 0.05 & 0.98 & 0.98 \\
\hline
\end{tabular}



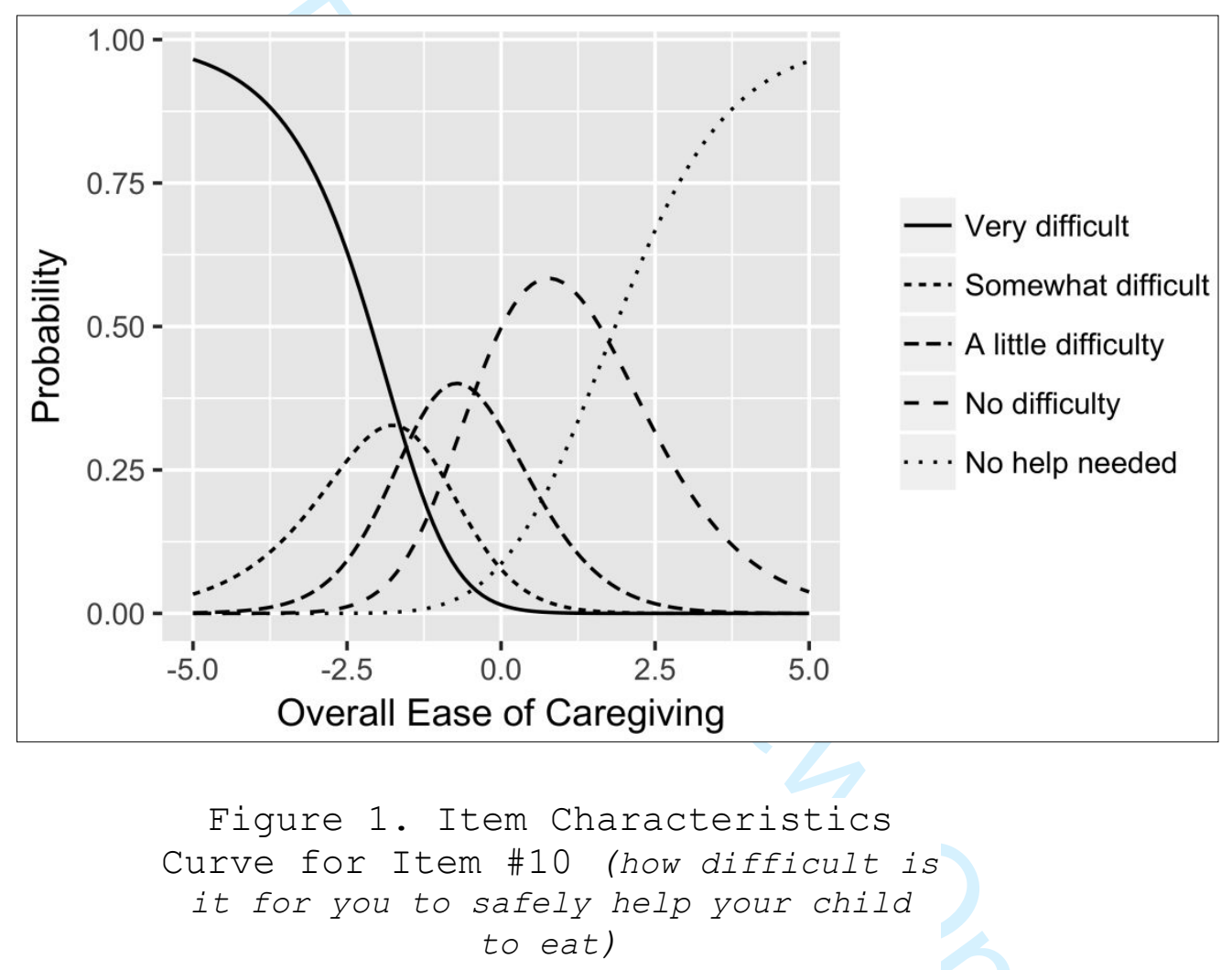


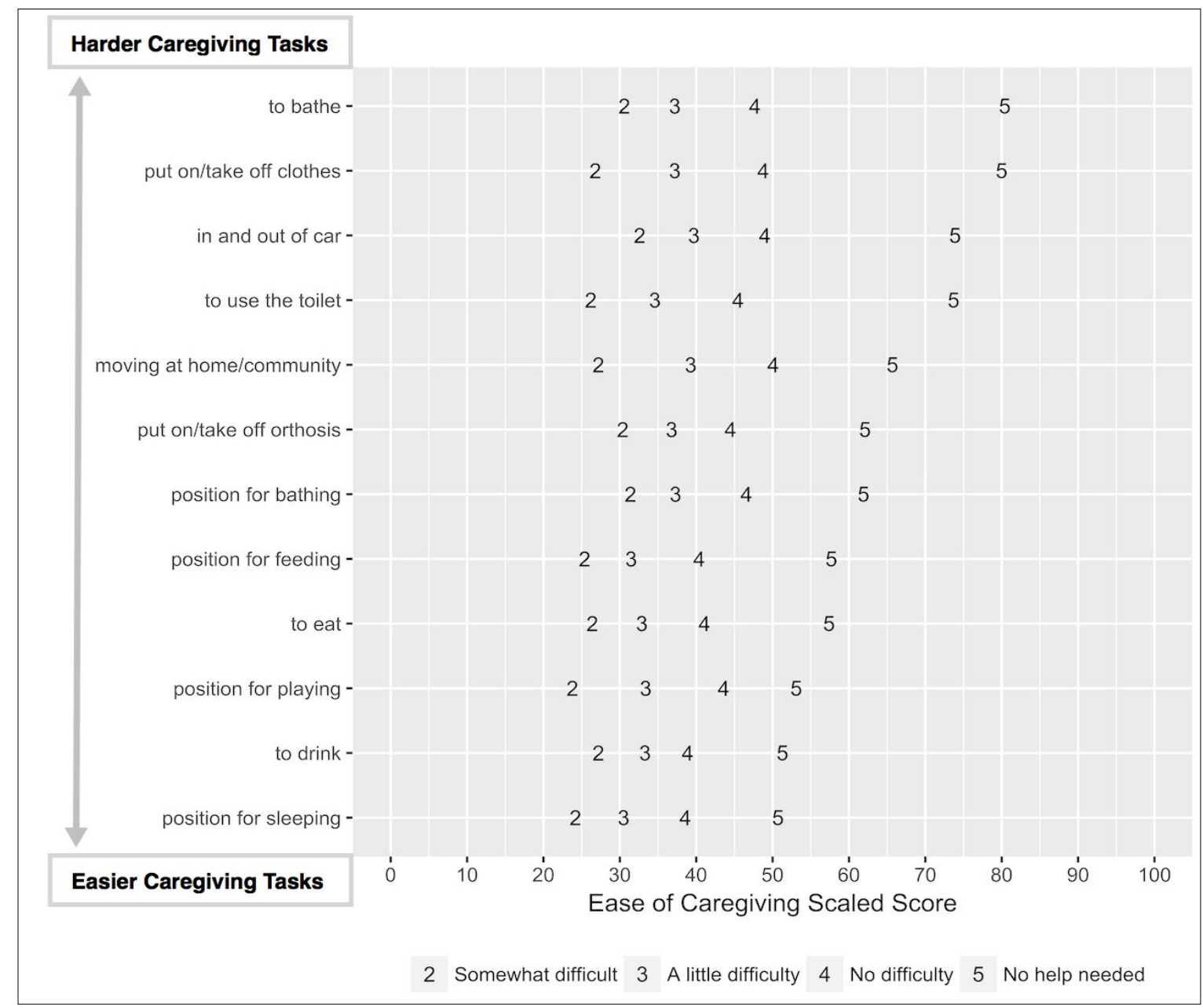

Figure 2. Item Response Map 


\section{Appendix}

Scoring System of Ease of Caregiving for Children Measure

\begin{tabular}{|cc|cc|c|c|}
\hline $\begin{array}{c}\text { Summed } \\
\text { Score }\end{array}$ & $\begin{array}{c}\text { Scaled } \\
\text { Score }\end{array}$ & $\begin{array}{c}\text { Summed } \\
\text { Score }\end{array}$ & $\begin{array}{c}\text { Scaled } \\
\text { Score }\end{array}$ & $\begin{array}{c}\text { Summed } \\
\text { Score }\end{array}$ & $\begin{array}{c}\text { Scaled } \\
\text { Score }\end{array}$ \\
\hline 60 & 100.0 & 43 & 46.3 & 26 & 32.4 \\
\hline 59 & 87.9 & 42 & 45.3 & 25 & 31.6 \\
\hline 58 & 80.6 & 41 & 44.3 & 24 & 30.8 \\
\hline 57 & 75.6 & 40 & 43.3 & 23 & 30.0 \\
\hline 56 & 71.5 & 39 & 42.5 & 22 & 29.0 \\
\hline 55 & 68.0 & 38 & 41.5 & 21 & 28.1 \\
\hline 54 & 64.9 & 37 & 40.8 & 20 & 27.1 \\
\hline 53 & 62.3 & 36 & 39.9 & 19 & 25.9 \\
\hline 52 & 59.9 & 35 & 39.1 & 18 & 24.6 \\
\hline 51 & 57.8 & 34 & 38.3 & 17 & 23.2 \\
\hline 50 & 55.9 & 33 & 37.6 & 16 & 21.4 \\
\hline 49 & 54.2 & 32 & 36.9 & 15 & 19.2 \\
\hline 48 & 52.7 & 31 & 36.2 & 14 & 16.0 \\
\hline 47 & 51.2 & 30 & 35.4 & 13 & 10.7 \\
\hline 46 & 49.8 & 29 & 34.7 & 12 & 0.0 \\
\hline 45 & 48.6 & 28 & 34.0 & & \\
\hline 44 & 47.4 & 27 & 33.2 & & \\
\hline \multicolumn{7}{r}{} & & & & \\
\hline
\end{tabular}

32 